\title{
Underlying Causal Factors Associated with Construction Worker Fatalities Involving Stepladders
}

Aneurin Grant, (University of West Florida, USA)

Jimmie Hinze, (University of Florida, USA)

\begin{abstract}
Stepladders are frequently utilized on construction projects as a means of access to elevation. Stepladder heights commonly range from 4 feet $(1.2 \mathrm{~m})$ to 14 feet $(4.3 \mathrm{~m})$. Since these heights are not extreme, there is a common misperception that stepladder use presents a low risk. On the contrary, extreme care must be exercised to ensure that work on stepladders is performed safely, as described in the conspicuously located recommendations and brightly-colored warnings that adorn virtually all newly-purchased equipment. Despite this, accidents involving stepladders occur on a regular basis. This study was conducted to better understand the underlying causes of these accidents. The narrative descriptions of 180 stepladder-related fatalities were obtained from the U.S. Occupational Safety and Health Administration and were analyzed to identify the at-risk behaviors that preceded the fatality incidents. The results showed that most of the incidents should have been anticipated and could have been avoided. Unsafe practices such as improper lockout-tagout of electrical equipment, loss of balance, working on a folded stepladder, over-reaching, straddling the ladder, "walking" the ladder, poor footing, and unstable/shifting ladders, among others were identified. Virtually all of these fatalities could have been avoided by adhering to the guidelines posted on the stepladders and by complying with basic safe construction practices.
\end{abstract}

Keywords: Accident causation, Construction worker fatalities, Safe work practices, Stepladders

\section{Introduction}

On building construction projects many different crafts are commonly involved and they perform many different tasks. Much of the work is performed at slight elevations and over a relatively short period of time. These tasks are often performed above the finished ceiling height, and include the installation of electrical lines and fixtures, plumbing lines, ductwork, insulation, sprinkler systems, and dropped ceilings. In many instances, the work performed cannot be completed at a single point in time, i.e., some workers may return to the same elevated location on a number of occasions before the installation is complete. When these individual tasks are performed in a short period of time, it is common for workers to perform the work with the use of stepladders, a temporary support system that can be set up and transported quickly.

Stepladders on construction projects have broad utility. Depending on their height, stepladders make it possible for work to be performed at elevations of a few feet to about 14 feet $(4.3 \mathrm{~m})$ or more. It is common for stepladders to be used by electricians, sheetmetal workers, carpenters, sheetrock installers, painters, plasterers, wallpaper hangers, plumbers, sprinkler installers, and many other trades.

Stepladders have been in wide usage on construction projects for many years; however, the use of stepladders is inconsistent in the industry. Accidents involving stepladders still occur and some of these result in fatalities. 
This study was undertaken to identify the causal factors of stepladder fatalities, and more broadly, the initiating factors in stepladder accidents. This research objective was pursued through the examination of narrative descriptions of fatality cases, considering both the physical conditions that might have contributed to the incident, and the procedures taking place at the time of the fatality incident. An additional objective of this study was to determine if typical manufacturers' warnings and instructions concerning the safe use of stepladders were adequate, or if worker error and improper use were more likely to explain the causes of stepladder fatality incidents.

\section{Literature Review}

Falls from elevation are the most common cause of construction worker fatalities. A study of U.S. construction worker fatalities that occurred from 2007 through 2009 revealed that $41 \%$ of those fatalities were due to falls (Hinze and Coates 2011). Of these fall fatalities, 13 percent involved ladders. In addition, more than one of every seven ladder-related fatality cases involved stepladders. It should be noted that most of the ladder-related fatalities involved extension ladders. Stepladders are generally of a lower height than typical extension ladders, and would be expected to be involved in fewer fatalities. In an earlier study of the causes of construction worker fall deaths it was found that $11.33 \%$ of the fatalities were the result of falls from ladders (Huang and Hinze 2003). Any differences between these statistics have not been determined to be significant.

The dangers associated with the use of ladders have been examined in prior research and are well-documented (Sharp, 2004). Some have attempted to quantify the epidemiological aspects of ladder injuries. Fractures were the most likely injuries to occur from ladder use, and the body parts most likely to be injured were the extremities. Male workers had a higher incidence of injuries associated with ladder use than women, and hospital admission rates increased as the elevation of the falls increased (D'Souza et al, 2007). This latter finding seems to corroborate the findings of Hinze and Coates (2011), who stated that the use of extension ladders is more likely to cause a fatal accident due to the height of the equipment. A separate study observed a relationship between the injury pattern and the elevation of the fall, and that upper extremity fractures are the most likely type of injury (O'Sullivan et al, 2004; Mitra et al, 2007). Fractures are also cited as the most frequent type of injury by other researchers (Partridge et al, 1998; Smith et al 2006), while others found that sprains and contusions occur more frequently (Faegermann and Larsen, 2000; Faegermann and Larsen, 2001).

Some researchers have concluded that accidents are more likely to occur in certain demographics, specifically men (D'Souza et al 2007; Harvinder and Goldbloom, 2008), and older men (Camino et al, 2011; Mitra el al, 2007). Mitra et al. have suggested that intrinsic and extrinsic variables should be examined, which may identify a user's propensity to injury. Intrinsic factors include the individual worker characteristics that might influence the probability of being injured, such as the user's age, weight, and medical condition. Extrinsic conditions pertain more to the physical conditions existing when a task is being performed by the worker, including activity-related and environmental factors, such the task being performed and surface and other localized conditions. Cohen and Lin (1991) examined various extrinsic factors associated with falls from ladders, including overreaching (19\%). Faegermann and Larsen $(2000 ; 2001)$ also concluded that the majority of accidents occur when users reach too far sideways, causing the ladder to tip or slip. Partridge et al. (1998) determined that $79 \%$ of the injuries resulting from falls were caused by over-reaching or incorrect ladder placement.

Some researchers have examined ladder mechanics in an attempt to improve safety. Juptner (1976) studied the angle and slip coefficient of the rungs, in addition to the ladder's lateral stability. The "slip coefficient" for the anti-skid mechanisms has been studied in conjunction with several types of ladders of varying lengths (Hakkinen et al 1998).

Grant A and Hinze, J (2013) 'Underlying causal factors associated with construction worker fatalities involving stepladders', Australasian Journal of Construction Economics and Building, 13 (1) 13-22 
Countermeasures have also been proposed by Harvinder and Goldbloom (2008), who focused on user competency, personal protective equipment, as well as appropriate conditions, set-up and ladder design. Ladder mechanics have also been analyzed with a focus on the users center of mass or center of gravity, where it has been found that lateral stability is dependent not only on the users movements from side-to-side, but also on the height of the rung above the ground, a finding that suggests that the design of ladders might best be re-examined (Yang and Ashton-Miller, 2005). It should be noted that these prior studies have been focused primarily on the use of extension ladders.

Safety is also a serious concern as it pertains to the use of stepladders. Many construction workers are injured and even killed in incidents in which stepladders are being used at relatively low elevations. These fatalities are especially unfortunate as it is widely felt that the safe use of stepladders is well-publicized. When a new stepladder is purchased, it is common for the stepladder to have several safety stickers attached to it. These stickers or signs on the stepladders are inscribed with safety rules from top to bottom, including instructions for setting up and using the stepladder safely. Examples of such rules include the following:

- Do not over-reach

- Do not straddle front and back

- Keep the body centered between the side-rails

- Do not step on the top two steps

- Do not walk or shift the stepladder while on it

- Set all four feet on a firm level surface

- Lock the spreaders when using the stepladder

- Wear slip-resistant shoes

- Abide by the weight limit

- Do not use folded stepladders as a single ladder

- Always face the stepladder when ascending or descending

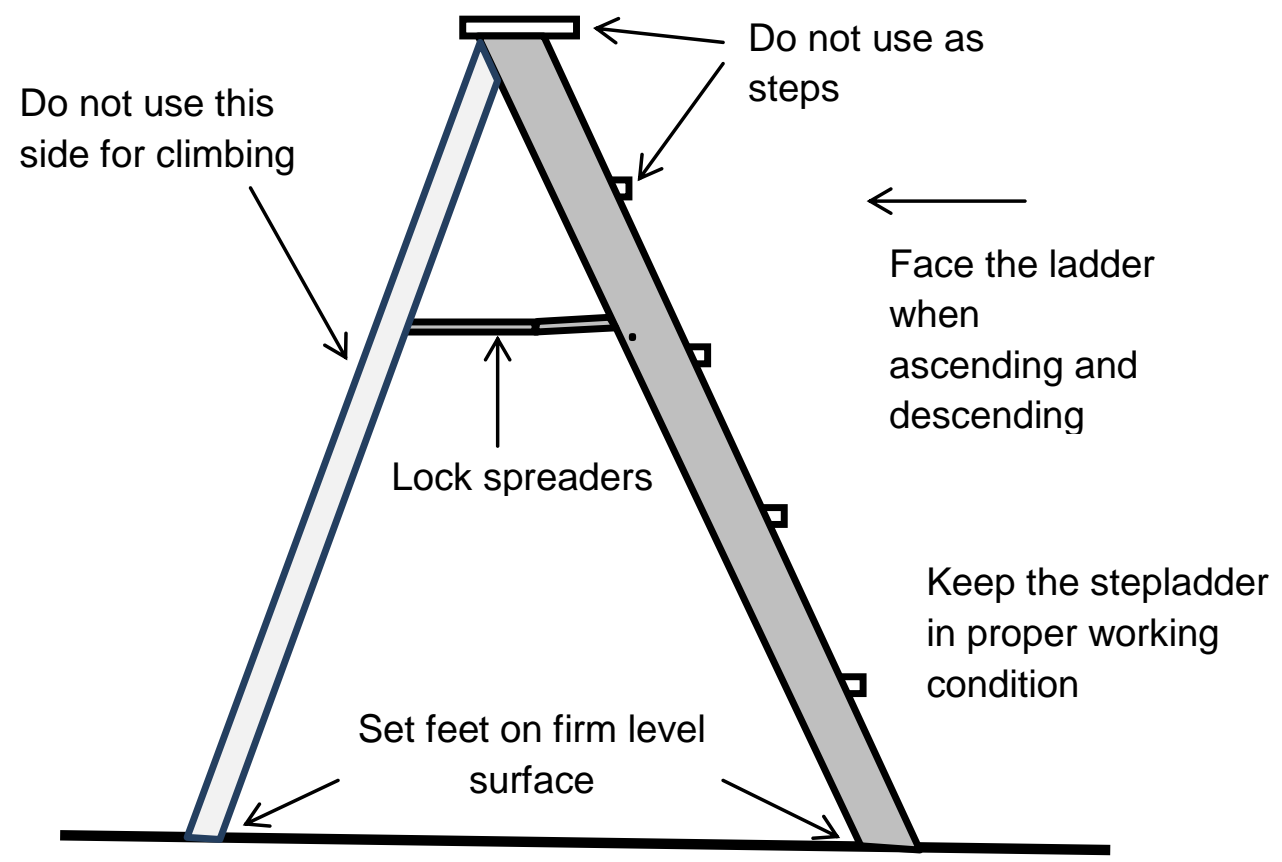

Figure 1 Safety guidelines for typical stepladders

Grant A and Hinze, J (2013) 'Underlying causal factors associated with construction worker fatalities involving stepladders', Australasian Journal of Construction Economics and Building, 13 (1) 13-22 
These instructions for the safe use of stepladders are clear and appear to be selfexplanatory, however, additional safe work practices involving stepladders can be identified, as not leaving tools or equipment on the top step or tray if the ladder is vacated for any period of time, cordoning off high-traffic areas such as doorways where stepladders must be positioned, and keeping the work area around the stepladder clear. Some of the guidance tips that are common on stepladder stickers are shown in Figure 1. Note that these instructions are valid for stepladders of any size.

Guidance is commonly provided on the inspection of stepladders, the selection of stepladders, and the proper care/storage of stepladders. Furthermore, the safe use of stepladders has been investigated at length and is well documented. Yet, it is not clear that established safety protocol is consistently being followed. On the contrary, it is believed that convenience and the rewards of expedient completion often influence the execution of construction work, including the use of stepladders. As such, one of the main research objectives of this study concerned the identification of workers' disregard for the recommended safety procedures.

\section{Research Method}

The data for this research were provided by the U.S. Occupational Safety and Health Administration (OSHA) Office of Statistical Analysis. The database of these fatality cases consisted of the inclusive years of 1990-2009. The database contained narrative descriptions of over 15,000 construction worker fatality incidents that occurred in the twentyyear period.

While the data for some years were coded, this was not done consistently for the various years. To ensure a consistent examination of the data, the causal factors were categorized according to the narrative descriptions of each fatality case. While the descriptions were not prepared in any particular format, it was felt that the most relevant information about the incidents could be obtained in this manner.

First, the incidents involving stepladders were indentified. Specifically, incidents in which stepladders were deemed to be part of the chain of events contributing to the incidents were extracted from the larger database. The causal factors for the stepladder incidents were coded so that the information could be examined through statistical analysis, in this case, with the use of the Statistical Package for the Social Sciences (SPSS). Information about the incidents extracted from the database included the heights of the stepladders, the tasks being performed on the stepladders, the material makeup of the stepladders, the causes of the incident, the types of projects being constructed, the heights of the falls (fall incidents only), and whether the incident was foreseeable and thereby preventable. There was considerable variation in the level of detail provided in the narrative descriptions. As a result, some incidents lacked sufficient information for the purposes of categorization. For example, not every description provided the material makeup of the stepladder, or the height of the ladder.

\section{Results}

A total of 180 fatality incidents were identified in which stepladders were involved. One of these incidents involved two fatalities, while all others consisted of a single fatality. In some cases, the stepladders were used in an inappropriate manner. Other cases, especially those involving electrical work, involved poor safety protocol when working on the stepladders. For example, some workers elected not to employ proper lockout/tagout procedures when working with electrical components while on a stepladder. While some workers died from heart attacks or heat stroke, these were not assumed to be closely-associated with the actual use of the stepladders and were not included among the final 180 cases, as the stepladders did not appear to be primary contributing factors in the incidents.

Grant A and Hinze, J (2013) 'Underlying causal factors associated with construction worker fatalities involving stepladders', Australasian Journal of Construction Economics and Building, 13 (1) 13-22 
The material makeup of stepladders might be an important selection criterion for some tasks, i.e., aluminum or metal stepladders are not advised for working in locations where electrical contact might be made. The material makeup of the stepladders was identified in 40 incident descriptions. If these incidents are considered to be representative, then most $(57 \%)$ stepladders are made of fiberglass, with the remaining stepladders being equally divided between wood and aluminum.

As previously noted, many different trades rely on the use of stepladders to perform at least some of their tasks at elevation. Electricians were most numerous among the victims. More than one-third of the victims were electricians, with nearly half dying from electrical shock, while most others died from falls, often caused by an initial electrical shock. Other trades that were involved in stepladder incidents included carpenters, demolition workers, heating ventilation and air conditioning (HVAC) workers, steel erectors, painters, insulation workers, window installers, drywallers, and others.

While stepladders are used most extensively on building projects, the stepladder incidents occurred in a variety of locations, including industrial, commercial and residential projects. Since stepladders are best suited for use on flat surfaces, it is logical that $77 \%$ of the incidents occurred indoors.

Workers typically work on stepladders to gain access to a work area that is at a slight elevation, often carrying their tools and materials with them as they ascend, as opposed to ascending the ladders and hoisting the tools and materials with the assistance of a coworker. In over half of the incidents, it was evident that the victims were carrying either tools or materials that compromised their ability to work safely on the stepladders.

The type of movement on the stepladders (ascending, descending or being stationary on the stepladders) by the workers who were fatality victims was provided for 140 incidents (there were no witnesses for 40 incidents). Of the 140 incidents, one worker lost his balance as he was descending the stepladder while facing away from the ladder, a practice that is clearly contrary to safe work procedures. In most of the remaining incidents workers were stationary, that is, not ascending, descending, nor reaching. When workers were stationery on the stepladders, they were often engaged in some type of work activity For example, in 31 instances the workers were engaged in cutting or drilling tasks. These activities often resulted in unexpected movement, which in turn precipitated fatal fall. These data are summarized in Figure 2.

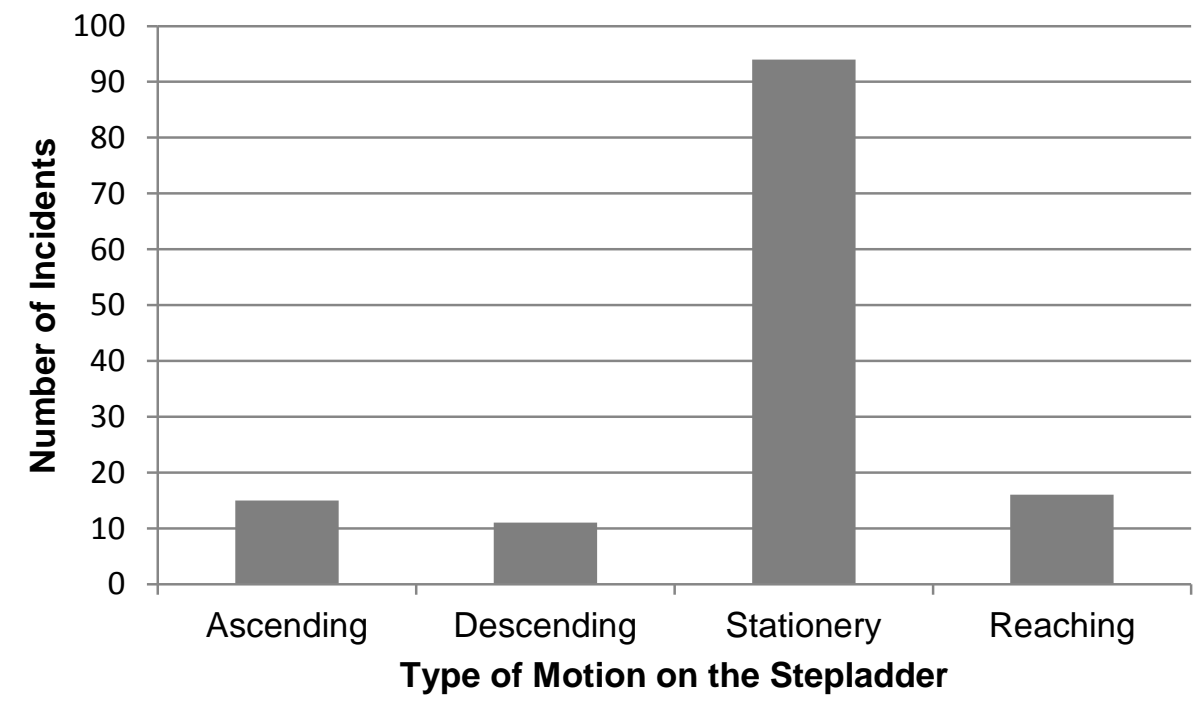

Figure 2 Type of worker motions at the time of the fatal incidents $(N=136)$

Grant A and Hinze, J (2013) 'Underlying causal factors associated with construction worker fatalities involving stepladders', Australasian Journal of Construction Economics and Building, 13 (1) 13-22 
The heights of the stepladders should be determined by the specific needs of workers. At times, the size of stepladder is determined by convenience, with workers choosing ladders based on simple availability. While nearly half of the stepladders were 8 feet $(2.4 \mathrm{~m})$ in length, they varied considerably, ranging from 3 feet $(0.9 \mathrm{~m})$ to 14 feet $(4.3 \mathrm{~m})$ in length (see Figure 3). The length of the stepladder is measured along the side rails. Thus, the height of a stepladder with 8 feet $(2.4 \mathrm{~m})$ long side rails will be slightly less than 8 feet tall when properly set up. Also, since the top two steps are not to be utilized for foot support, the highest standing point on an 8-foot ladder is about 5 feet-9 inches $(1.75 \mathrm{~m})$. Despite the relatively shorter heights involved with stepladders, 80 percent of the fatalities analyzed in this study were the result of falls.

Of the fall incidents, it was noted that in 21 incidents the fall height exceeded the height of the stepladder. This occurred when stepladders were placed next to open balconies, windows, elevator shafts, or some other opening. These falls exceeded the stepladder height from $2(0.6 \mathrm{~m})$ to 200 feet $(61 \mathrm{~m})$.

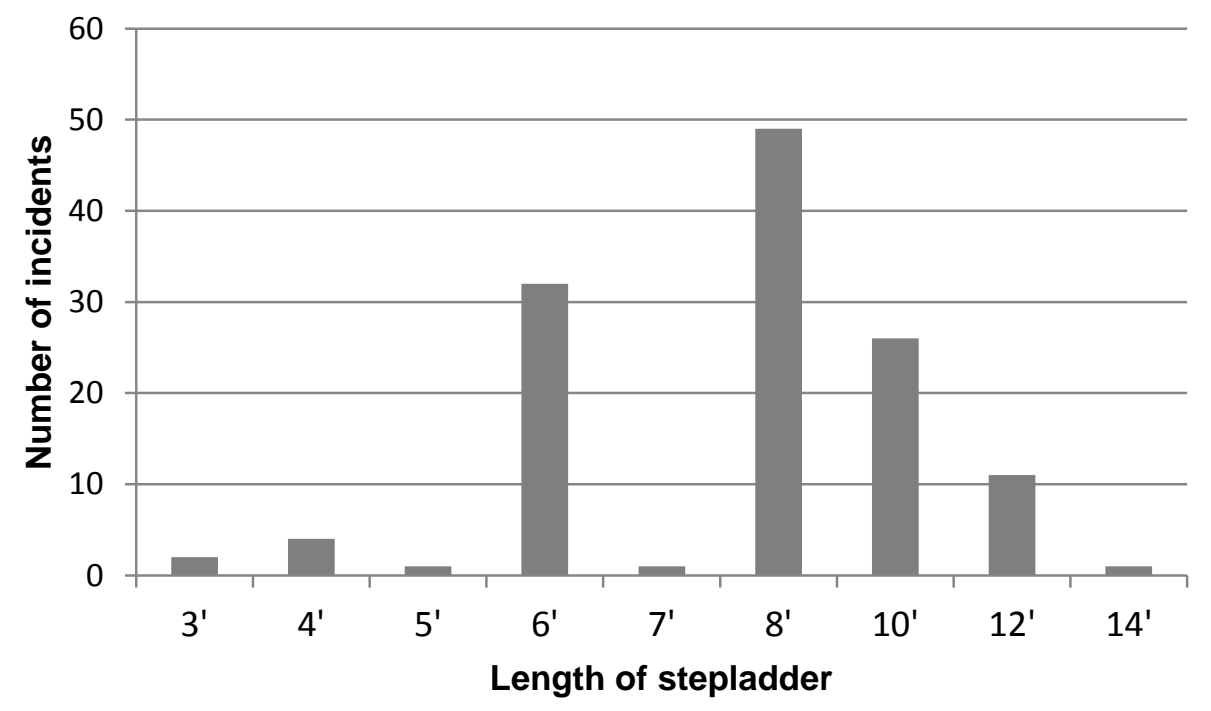

Figure 3 Length of stepladders involved in fatal incidents $(N=127)$

The performance of many different tasks was described in the narrative descriptions of stepladder incidents. Many fatalities were not a direct result of stepladder misuse. Rather, many fatalities occurred due to poor electrical safety and lockout/tagout procedures, whereby workers were electrocuted or shocked at elevation and subsequently fell. It is unclear whether these electrocutions and electrical shocks occurred due to incidental contact of energized circuits or materials, or if deliberate work was being performed on hot circuits. Similarly, the narrative descriptions of these incidents did not indicate whether proper lockout/tagout procedures were ignored as a matter of "convenience". As such, the findings of this study do not identify specific frequencies of chance versus overt negligence.

Several specific uses of stepladders are known to place workers at risk. Nonetheless, these unsafe uses continue to be commonplace on many construction sites. Some of these practices will be described more fully, as follows.

Electrocution: A total of 31 electrocutions (17.2\%) occurred while workers were working on stepladders. It was also evident that in many of these incidents the workers recognized the electrical hazards, but they ignored them for some reason. It is common practice to lock out electrical current before performing work on a "live" wire or fixture. While aluminum stepladders would be suspected of presenting a greater electrical hazard than the use of wood or fiberglass stepladders, this did not appear to be a factor in the electrocution

Grant A and Hinze, J (2013) 'Underlying causal factors associated with construction worker fatalities involving stepladders', Australasian Journal of Construction Economics and Building, 13 (1) 13-22 
incidents. In many instances, the electrical current did not pass through the stepladder, but to another grounded source that the worker happened to touch. A typical case is the following:

An electrician was working from a 6-foot $(1.8 \mathrm{~m})$ stepladder installing a lighting fixture. The lighting circuit was energized while he was working on it. The electrician contacted an energized part of the circuit and was electrocuted.

Electric Shock/Fall: There were 30 incidents (16.7\%) in which a worker received an electric shock, but was not electrocuted while working on the stepladder. In these cases the electrical shock was followed by a fatal fall. The following is a typical case:

An electrician was working from a 10 -foot $(3 \mathrm{~m})$ high stepladder, installing overhead lighting fixtures in a new department store under construction. The electrician was working with the circuit energized, in violation of company policy. He apparently received an electric shock, which caused him to fall from the stepladder to the smooth concrete floor several feet below. (The ladder was not defective or damaged in any way.) The electrician struck his head on the concrete floor and died as a result of the fall.

Loss of Balance: Several of the incident descriptions mentioned that the workers fell from stepladders when they lost their balance. For 24 worker deaths, the cause was noted as loss of balance, without describing the specific cause of the loss of balance. In many of these instances, there were no witnesses. The following is a typical description:

Worker was standing on a stepladder preparing to use a cutting torch. He lost his balance, fell onto the concrete floor, and was killed.

Leaning a Folded Stepladder: Because of their basic configuration and the locking of the spreaders (see Figure 1) stepladders may be separated from a facing wall. In some circumstances, this distance can be problematic. Space permitting, this problem can be addressed by turning the stepladder 90 degrees so that work can be performed directly to the side of the stepladder. In no circumstance is it acceptable to fold the stepladder and lean it against the wall so that the work can be more easily accessed. The feet of stepladders are not designed for this type of use. Such a use can result in the stepladder slipping on the floor if it is placed at a flat angle, or if the angle is too sharp, the worker's center of gravity might cause the worker to fall backwards. This is similar to what happened to 10 construction workers, as described in the following example:

Worker was working from a folded 6-foot $(1.8 \mathrm{~m})$ stepladder on top of a dust collector system. He lost his balance as the ladder tipped. He fell approximately 14 feet $(4.3 \mathrm{~m})$ to the concrete pad and died.

Overreaching on the Stepladder: In many ways, the stability of a stepladder is dependent on the user's center of gravity. There is a common "belt buckle rule" that states that the belt buckle of the worker is to always remain between the side rails. In other words, once the belt buckle is beyond the side rail, the worker's position will become unstable. This may occur when work is performed in a linear fashion and the unfinished work extends beyond the side rails. It might be tempting for the worker to stretch just a little bit in order to get a little extra work performed before moving the ladder, but this can be dangerous. The worker should descend the stepladder, realign the stepladder and then ascend the stepladder to perform the next task. In many cases, workers attempt to gain efficiency by minimizing the movement of stepladders. Of course, these attempts to gain efficiency imply the unsafe practice of overreaching, which makes a fall from elevation more likely. This occurred nine times in the database. A particularly egregious example is as follows:

Grant A and Hinze, J (2013) 'Underlying causal factors associated with construction worker fatalities involving stepladders', Australasian Journal of Construction Economics and Building, 13 (1) 13-22 
A worker was installing a crown molding piece from a tubular welded scaffold that was approximately 16-feet $(4.9 \mathrm{~m})$ high and placed around a corner. He placed a stepladder on a balcony bench to extend his reach. Other workers in the area felt that the worker had lost his balance when the ladder moved as he was reaching. He fell approximately 15 feet $(4.6 \mathrm{~m})$ to the ground and was killed.

Straddling the Ladder: There were seven instances in which workers used the top step of a stepladder as a seat, generally with one leg straddling each side of the stepladder. This is of course a noncompliant use of the equipment. It is not clear how these falls were initiated in these seven incidents, but it is possible that the workers shifted their weight in such a manner that they initiated a fall.

Standing on the Top Step: The top two rungs are specifically not to be used as steps (see note on Figure 1), as clearly indicated on the safety signs on the side rails of newly purchased stepladders. This rule was violated by seven workers who died when they fell from the stepladders. A typical case is as follows:

The worker was installing insulation in the garage of a single family dwelling. He was standing on the top step of a 10 -foot $(3.0 \mathrm{~m})$ stepladder when he fell to the concrete slab floor striking his head on the floor and succumbing to head trauma.

Walking the Stepladder: For some types of work, brief tasks are performed while working on a stepladder. As the next task may be a short distance away, workers may be reluctant to descend the stepladder, reposition it and ascend the stepladder to continue the task. Some workers find the constant descending and ascending effort to be laborious and timeconsuming. As such, some have modified the stepladders so that the locking device is inoperative. They can then shift their weight on the stepladder and "walk" the stepladder to the next location. There are different ways of "walking a ladder", including raising the stepladder so all the support is on two legs and then shifting the weight from one side to the other to advance the stepladder. Some workers "walk" with the stepladders by straddling the top of the stepladder and shifting the weight from one pair of legs to the other. Both of these practices are considered to be unsafe. This practice was found to result in the death of four construction workers.

Defective Stepladder: Before each use, stepladders should be inspected for their integrity. The rungs should be tightly fixed, the locking device must be operational, and there should be no broken components. The consequences of defective components are self-evident, yet this was noted as the cause of death for one construction worker.

Lock Spreader not Locked: The lock spreader has the function of keeping the rails of the stepladder at a fixed distance. If the lock spreader is not fully locked, the rails of the stepladder are closer together and this reduces the stability of the stepladder as the rails will not be fixed in place. There was one instance, resulting in a worker death, where the lock spreader was not properly positioned.

Other Causes: There were many other causes of the incidents involving stepladders. In some instances, the cause could not be ascertained due to the lack of witnesses. In some instances, the causes were apparent and should have been anticipated by the workers. For example, the following case involves wind which might have been predicted:

Two workers were working from stepladders moving sheets of siding. A strong gust of wind apparently caused one of the ladders to tip. The worker jumped free of the stepladder and landed on his feet after dropping 3 to 4 feet. His forward momentum caused him to continue pitching forward striking the top of his head on the asphalt paving knocking him unconscious. He was pronounced dead 2 hours later.

Grant A and Hinze, J (2013) 'Underlying causal factors associated with construction worker fatalities involving stepladders', Australasian Journal of Construction Economics and Building, 13 (1) 13-22 


\section{Conclusions}

The examination of the narrative descriptions of the fatalities involving stepladders revealed that almost all (95\%) of the incidents could have been anticipated, and consequently avoided. Workers often took short-cuts and ignored safe work practices. This may be done in an effort to save time, but ignores the risks to workers' lives. Workers may be at least partially responsible for their own deaths by employing poor work practices. The manufacturers' instructions and warnings commonly affixed to stepladders appear to be more than adequate. Rather, compliance is the problem. In fact, many of the causes of the fatalities involving stepladders were in direct contradiction of the stated instructions and guidance commonly affixed to the stepladders. The question arises as to why these instructions were not followed. Perhaps workers become accustomed to performing work while employing unsafe procedures. Employers cannot let this happen. There is no indication that there is any fault in the design of stepladders.

It may also be concluded that exposure to energized electrical components poses a tremendous risk to workers on step ladders, as is evident in 61 of the fatality incidents discussed in this study. Logically, this type of exposure is germane to electrical workers. However, many other trades are involved in tasks that expose the workers to energized electrical components. For example, workers installing sheet metal ductwork, fire sprinklers, ceiling tile and audio visual equipment may also be exposed to energized components, often through inadvertent contact.

Construction firms should carefully review their internal work rules and procedures. Perhaps the first serious consideration should be whether alternative means are available for workers to work at elevation. Consideration should be given to the use of platform scaffolds or movable stair platforms. Some construction firms have been known to ban the use of stepladders on their projects.

Additional consideration should be given to lockout/tagout procedures. The results of this study suggest that contact with energized components is a major risk associated with the use of step ladders. A re-examination of lockout/tagout policies and procedures may identify unknown, hazardous conditions. Moreover, the identification of such hazards may help to clarify where and when it is appropriate to turn the power off, without impeding the progress of work.

When stepladders are to be employed on a project site, it is imperative that workers are required to follow good safe work procedures. This begins with a clear orientation on the proper use of stepladders and strict enforcement of the safe work procedures.

\section{References}

Huang, X. and Hinze, J. (2003) 'Analysis of Construction Worker Fall Accidents', Journal of Construction Engineering and Management, ASCE, 129 (3)

Hinze, J. and Coates, W. (2011) 'Trends in Construction Work Fatalities', Proceedings of CIB W099 Prevention: Means to the End of Injuries, IIInesses, and Fatalities, Washington, DC, August 24, 2011

Camino Lopez MA, Ritzel DO, Fontaneda Gonzalez I, Gonzalez Alcatara OJ (2011) 'Occupational accidents with ladders in Spain: Risk factors', Journal of Safety Research, 42, 391-398

Cohen, HH and Lin, L. (1991) 'A Scenario Analysis of Ladder Fall Accidents', Journal of Safety Research, 22 (1), 31-39

D'Souza AL, Smith GA, Trifiletti, LB (2007) 'Ladder-Related Injuries Treated in Emergency Departments in the United States, 1990-2005', American Journal of Preventative Medicine, $32(5)$

Grant A and Hinze, J (2013) 'Underlying causal factors associated with construction worker fatalities involving stepladders', Australasian Journal of Construction Economics and Building, 13 (1) 13-22 
Faegermann C, Larsen LB (2001) 'The mechanism and severity of nonoccupational ladder fall injuries', Journal of Safety Research, 32, 333-343

Faegermann C, Larsen LB (2000) 'Non-occupational ladder and scaffold fall injuries' Accident Analysis and Prevention, 32,745-750

Hakkinen KK, Pesonen J, Rajamaki E (1988) 'Experiments on safety in the use of portable ladders', Journal of Occupational Accidents, 10, 1-19

Harvinder SB, Goldbloom D (2008) The Journal of Trauma, Injury, Infection and Critical Care, June 2008

Juptner H (1976) 'Safety on ladders: an ergonomic design approach', Applied Ergonomics, 7 (4), 221-223

Mitra B, Cameron PA, Gabbe BJ (2007) 'Ladders Revisited', Medical Journal of Australia, $186(1)$

O'Sullivan J, Wakai A, O'Sullivan R, Luke C, Cusack S (2004) 'Ladder fall injuries: patterns and cost of morbidity', Injury: International Journal of the Care of the Injured, 35, 429-431

Smith GS, Timmons RA, Lombardi DA, Mamidi DK, Matz S, Courtney TK, Perry MJ (2006) 'Work-related ladder fall fractures: Identification and diagnosis validation using narrative text', Accident Analysis and Prevention, 38, 973-980

Partridge RA, Virk AS, Antosia RE (1998) 'Causes and Patterns of Injury from Ladder Falls', Academic Emergency Medicine, 5, 31-34

Sharp D (2004) 'Four Up, One Back - And No One Off', The Lancet, 363, 1252

Yang BS, Ashton-Miller JA (2005) 'Factors affecting stepladder stability during a lateral weight transfer: A study in healthy young adults', Applied Ergonomics, 36, 601-607 